\title{
Importance of Objective and Subjective Measurement of Food Quality and their Inter-relationship
}

\section{Singham $\mathrm{P}^{1}$, Birwal $\mathrm{P}^{2 *}$ and Yadav $\mathrm{BK}^{3}$}

${ }^{1}$ IICPT, Tamil Nadu, India

${ }^{2} \mathrm{NDRI}$, Bengaluru, Karnataka, India

${ }^{3}$ Department of food packaging and system development, IICPT, Tamil Nadu, India

\begin{abstract}
Sensory properties of product are the most vital attributes, as they are most apparent to consumers. New era required new methods and tools to understand both the product and consumers. Objective measurements are more rapid, reliable and repeatable, but subjective also cannot be ignored. Subjective sensory analysis can be correlated with objective analysis. Different statistical tools and mathematical modelling is useful to correlate the instrument measurement with panel measurements. Subjective measurement can also be modulated by use of different psychophysical model and understanding of fundamental physical behaviour of food in mouth. Objective measurement is standardized by the subjective measurements, as only consumer perceive which is acceptable or not, and the acceptable value can be given as standard for objective measurements in routine testing. Further research to develop more inter relationship between these two is needed.
\end{abstract}

\section{Keywords: Sensory; Objective; Subjective}

\section{Introduction}

Food quality can be defined as the degree of excellence of food includes factors such as taste, appearance, and nutritional quality, as well as in bacteriological or keeping quality. Food quality goes hand in hand with food acceptability, and it is important that quality is monitored, both from a food safety standpoint and to ensure that the public likes a particular product and will come to select it. Sensory analysis plays major roll in defining food quality. Sensory analysis is not psychophysics or vice-versa. Sensory science is a multidisciplinary area comprising measurement, interpretation and understanding of human responses to product properties as perceived by the senses such as sight, smell, taste, touch and hearing.

A philosophy for sensory science relies heavily on empirical and theoretical contributions from many professionals such as physiologists, psychologists, philosophers, anthropologists, marketing scientists as well as chemists, technologists and data analysts [1].

Psychophysics is 'the study of the relationship between measurable stimuli and the corresponding responses' (International Organization for Standardization, Standard 5492/1, 1977). From today's point of view, psychophysics and sensory analysis appear conjoined, at least from the vantage point of sensory analysis. Psychophysical thinking has not only entered sensory analysis, but also shaped some of the ways that modern day sensory analysts conceptualize their problems and go about solving them. But this is not always the case. The rapprochement of the two fields has only gradually developed as sensory analysis has come to accept psychophysical thinking [2]. Psychoreheology is major branch of sensory analysis.

Psychorheology: There are two types of definitions given to psychorheology.

1. Psychorheology is a branch of psychophysics dealing with the sensory perception of rheological properties of foods

2. Psychorheology is the relationship between the consumer preferences and rheological properties of foods.

Food quality has both subjective and non-subjective aspects. Appearance, texture and flavour are largely subjective attributes whereas nutritional quality and bacterial quality are not. Texture is a key quality factor for acceptability of food stuff. Quality attributes like thickness, spread ability, and creaminess are extremely important to the acceptance of semisolid food products by consumers. Rheological behaviour is associated directly with texture; taste and mouth feel [3-7].

\section{Subjective Measurement}

Subjective evaluation of food may include evaluation that may utilize one or more of the different tests. Sensory evaluation can be seen as a link between research and development, with a focus made on technical aspects of food, and consumer and marketing research, with a focus on consumers' behaviour and psychology [8]. They measure the reaction to stimuli resulting from the use or consumption of a product through analytical and/or affective tests. Traditionally, analytical tests (discriminative and descriptive) are performed with trained panels whereas affective tests are run with consumers [9]. Ballots which are, a sheet of paper which evaluators receive sample information and instruction and which observations are recorded during a sensory test. Describing the sensory characteristics of products has been an integral part of the food and beverage industry since long ago. Information obtained from the description of the sensory characteristics of food and beverages enable companies to make more informed business decisions [9]. Sensory profiling of a product can guide product development teams on what to change to match the consumer's desired sensory profile, to get closer to a benchmark, to detect detailed differences created by a change of an ingredient [10].

\section{Sensory Evaluation}

Sensory evaluation is defined as a scientific method used to evoke, measure, analyze and interpret those responses to products perceived *Corresonding author: Preethi Birwal, NDRI, Bengaluru, Karnataka, India, E-mail:
preetibirwal@gmail.com

Received May 11, 2015; Accepted July 09, 2015; Published July 16, 2015

Citation: Singham P, Birwal P, Yadav BK (2015) Importance of Objective and Subjective Measurement of Food Quality and their Inter-relationship. J Food Process Technol 6: 488. doi:10.4172/2157-7110.1000488

Copyright: $\odot 2015$ Singham P, et al. This is an open-access article distributed under the terms of the Creative Commons Attribution License, which permits unrestricted use, distribution, and reproduction in any medium, provided the original author and source are credited. 
through senses of sight, smell, touch, taste and hearing [9]. Rheology in sensory evaluation is used as an essential design tool in engineering food as it is important to processing, shelf stability and sensory perception, including texture and mouth feel, and it can probe the overall structure as well as the interplay between individual colloidal components [11].

A number of processes occur while food is being masticated, including deformation, flow, comminuition, mixing and hydration with saliva, and sometimes changes in temperature, size, shape, and surface roughness of the food particles [12]. All of these changes are recorded with great sensitivity by the human senses, but is difficult to measure in many of cases with instruments. The entire complex of events that occurs during mastication cannot be measured completely by instruments. There is no instrument available that has the sophistication, elegance, sensitivity, and range of mechanical motions as the mouth or that can promptly change the speed and mode of mastication in response to the sensations received during the previous chew. Modern sensory texture analysis was started by Dr Szczesniak's group at the General Foods Corporation Technical Center in Tarrytown, New York in the early 1960s. (General Foods Corporation has since become part of Kraft Foods.) (Food Texture and viscosity).

It mainly determines

- Parameters of difference (eg. Taste, odour, juiciness, texture etc.)

- Extent of difference.

- Consumer preferences

\section{Types of sensory tests}

1. Difference / Discriminative tests

2. Rating test

3. Sensitivity tests

\section{Objective Measurement}

Objective test measures one particular attribute of a food rather than overall quality of the product. In the case of new product development it is necessary to change the existing product, for that it is necessary to see acceptance of consumer and only objective testing is not sufficient, even it may be reliable.

Certain principle must be emphasized when considering objective tests to evaluate the quality of food product:

- The objective test must be appropriate for the food product being tested. In other words, it must measure an attribute of the food that has a major effect on quality.

- The objective tests results should be correlated with sensory testing of similar product to make sure that the test is a reliable index of quality of the food.

- Most objective test used to assess food quality empirical that is they do not measure an absolute property of the food. However the results are still meaningful, as long as instruments are calibrated with materials that have similar properties to the foods under test.

- Objective test include all types of instrumental analysis including laboratory test to determine chemical decomposition, nutrient composition and bacterial composition.

- Objective tests are repeatable and are not subject to human variation. If the equipment is properly maintained and is used correctly, it should give reliable results.

- Objective tests are necessary to identify contaminants in food and to reveal faulty processing methods as well as testing of deterioration and rancidity. Objective testing is must for routine quality control of foods and food products. However they must be correlated with sensory testing, because no single objective test can measure overall acceptability of a specific food or food product.

- Objective evaluation of food involves instrumentation and use of physical and chemical techniques instead of variable human sensory organs to evaluate food quality.

\section{Subjective and objective evaluation comparison}

Both sensory evaluation and objective evaluation of food quality are essential in food industry in order to routinely monitor food quality and to ensure that the foods being produced are acceptable to the customer. These two methods of evaluation are complementary to each other.

Sensory testing is expensive and time consuming, because panellists are required to test a single product in order for the results to be meaningful. On the other hand, objective testing if efficient and, but after the initial purchase of the needed equipment, also inexpensive. One can usually perform an objective test on many samples in a day, whereas it may take a day to perform a complete sensory test on line or two sample. Objective samples give repeatable results, whereas sensory test may give variable results due to variation of human responses and opinions.

While sensory evaluation gives a judgement of the overall acceptability of a product, and objective method to evaluation is only able to measure one aspect of food, and this may not always be sufficient to determine whether a quality of the product is acceptable. The only true judge ofthe acceptability of a food product is a consumer. Therefore, objective test must correlate with sensory tests to give a reliable index of food quality.

Objective test are essential for routine quality control of food products, however, sensory evaluation of product research and development. Only consumers can tell whether there is a perceivable difference in a product when the formulation or packaging is changed, and only consumers can determine whether a new product is acceptable or preferred over another brand (Table 1).

\section{Interrelationship between sensory and objective measurement of food}

Pang born [13] stressed that the senses behave as integrators in a multivariate and relative way, while instruments are characterized by being separators in a univariate and absolute way. Nevertheless, in most of the sensory literature there is a tendency to deal with one sense modality at a time, not even reacting upon interactions from other senses, e.g. the colour of a product influences the perception. During the history of instrumental development, we have viewed many instruments as elongation of the individual senses.

The combination of time and high cost associated with sensory perception has motivated the development and widespread use of empirical mechanical tests which correlate with sensory perceptions of food texture [14-16].

Subjective viscosity is the most studied sensory attribute in the fluid foods, since it is normally recognized that the rheological properties 
Citation: Singham P, Birwal P, Yadav BK (2015) Importance of Objective and Subjective Measurement of Food Quality and their Inter-relationship. J Food Process Technol 6: 488. doi:10.4172/2157-7110.1000488

Page 3 of 7

\begin{tabular}{|l|l|}
\hline Subjective /Sensory analysis & Objective analysis \\
\hline Uses individuals & Uses equipment \\
\hline Involves human sensory organs & Use physical and chemical techniques \\
\hline Results may vary & Results are repeatable \\
\hline $\begin{array}{l}\text { Determines human sensitivity to } \\
\text { changes in ingredients, processing or } \\
\text { packaging }\end{array}$ & $\begin{array}{l}\text { Need to find a technique appropriate for } \\
\text { the food being tested. }\end{array}$ \\
\hline Determines consumer acceptance & $\begin{array}{l}\text { Cannot determine consumer acceptance } \\
\text { unless correlated with sensory testing }\end{array}$ \\
\hline Time-consuming and expensive & $\begin{array}{l}\text { Generally faster and cheaper, and more } \\
\text { efficient then a sensory testing }\end{array}$ \\
\hline $\begin{array}{l}\text { Must for product development and for } \\
\text { good marketing of new products }\end{array}$ & Essential for routine quality control \\
\hline
\end{tabular}

Table 1: Comparison between subjective and objective analysis.

liquid food materials have a profound impact on the perceived texture by the consumers [17-19]. Textural properties of food are used by consumers as key quality indicators that contribute to product acceptability [20,21]. Early studies by Shama et al. [17] initiated the semi quantitative design rules firstly in reference to semisolid and liquid food materials.

This was then followed by mathematical models that areable to predict liquid perception in the mouth, developed by Kokini et al. [19].

Psychophysical models have been used to evaluate the effect of external stimulus on the impression of subjective intensity. According to the psychophysical power law model, the sensation magnitude, $\psi$, grows as a power function of the stimulus magnitude, $\varphi$.

$$
\psi=a \varphi^{b}
$$

The constant $a$ depends on the units of measurement. The value of exponent $b$ serves as a signature that may differ from one sensory continuum to another.

The exponent of the power function determines its curvature:

$b \sim 1.0$ sensation varies directly with the intensity of stimulus

$b>1.0$ concave upward, sensation grows more and more rapidly as the stimulus increases

$b<1.0$ downward curvature, sensation grows less and less rapidly with increasing stimulus

The linear form of the power law model gives the simple relation between stimulus and sensory response:

$$
\log \psi=\log a+b \log \varphi
$$

According to this linear relationship, equal stimulus ratios produce an equal subjective ratio, which means a constant percentage change in stimulus produces a constant percentage change in the sensed effect. Once the appropriate sensory perception mechanisms are identified they can be linked to the operating conditions of each sensory test through psychophysical models.

The sensory thickness is one of the most important textural attributes of semisolid foods. Predictive correlation between thickness and rheological properties of foods can be developed and for that, it is necessary to understand the deformation process in the mouth. Kokini [19] estimated sensory viscosity of liquid foods in the mouth from the fundamental physical properties of these fluids using the lubrication theory. Kokini et al. [19] showed that sensory thickness was perceived as the shear stress between the tongue and the roof of the mouth, smoothness as the inverse of the boundary force, and slipperiness as the average of the reciprocal boundary friction and hydrodynamic forces.
Elejalde and Kokini [7] approximated the roof of the mouth and the tongue to squeeze flow solution assuming parallel plate geometry to estimate the sensory viscosity in the mouth (Figure 1).

The proposed psychophysical model is:

Subjective viscosity $=a$ (Shear stress in the mouth $)^{b}$

Elejalde and Kokini [7] estimated the sensory viscosity of low calorie viscoelastic syrups in the mouth, while pouring the syrup out of a bottle, and spreading over a flat surface from the fundamental physical properties of these fluids. In order to estimate the sensory viscosity during pouring, the flow conditions were approximated by an inclined trough, with circular channel profile identical to that on the neck of the bottle (Figure 2) with incompressible, steady and fully developed flow.

The following psychophysical model was proposed:

Subjective viscosity $=a\left(A c^{b}\right.$

Where $A c$ is the degree of fill of the flow channel, or the crosssectional area of the neck of the bottle that fills up when a given amount of syrup is being poured.

In a third study, Elejalde and Kokini [7] approximated the flow during spreading by a squeeze flow solution, where the height of liquid under gravitational forces provides the squeezing force at any instant. The squeezing force is equal to the hydrostatic force exerted by the height of the syrup in puddle (Figure 3). Thus we can say that transient force exists.

The proposed psychophysical model is therefore:

Subjective viscosity $=a(1 / \text { Radial Growth of Syrup Puddle })^{b}$

All of the sensory cues were found to be appropriate in estimating the sensory response of subjective viscosity in the mouth, pouring out of the bottle and spreading over a flat surface. Oral sensory viscosity correlated with the shear stress in the mouth $\left(R^{2}=0.96\right)$; pouring sensory viscosity correlated well with the cross-sectional area filled by the fluid at the neck of the bottle $\left(R^{2}=0.86\right)$ and spreading sensory viscosity correlated inversely with the radial growth of the spreading fluid puddle $\left(R^{2}=0.96\right)$. Figure 4 shows the correlations between sensory and experimental measures [7].
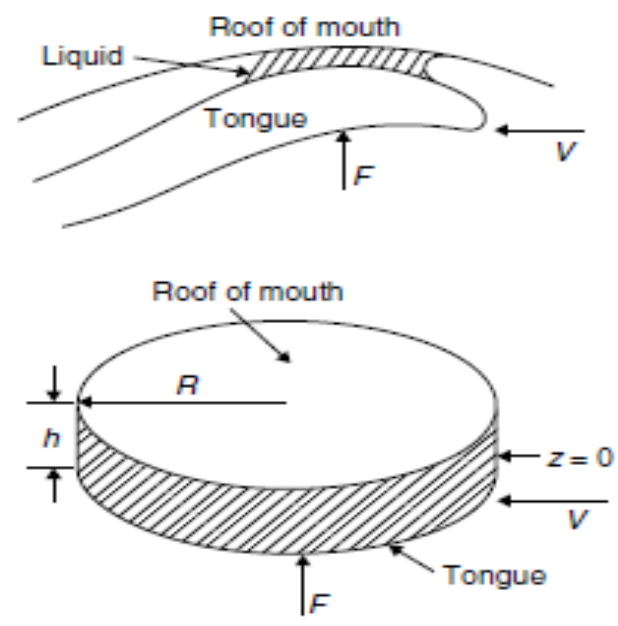

Figure 1: Model geometry of the mouth [6,7]. 


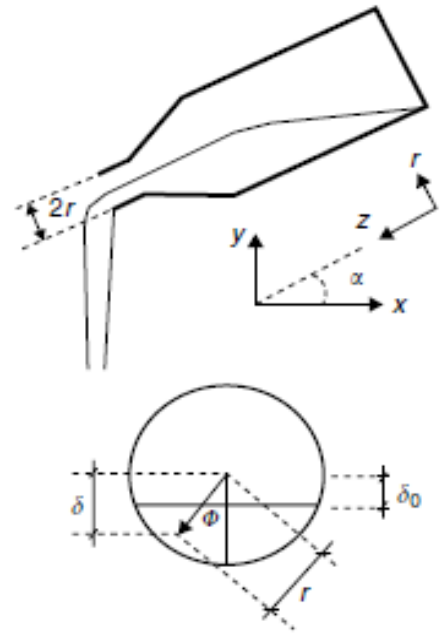

Figure 2: Model geometry for flow out of a bottle $[6,7]$.
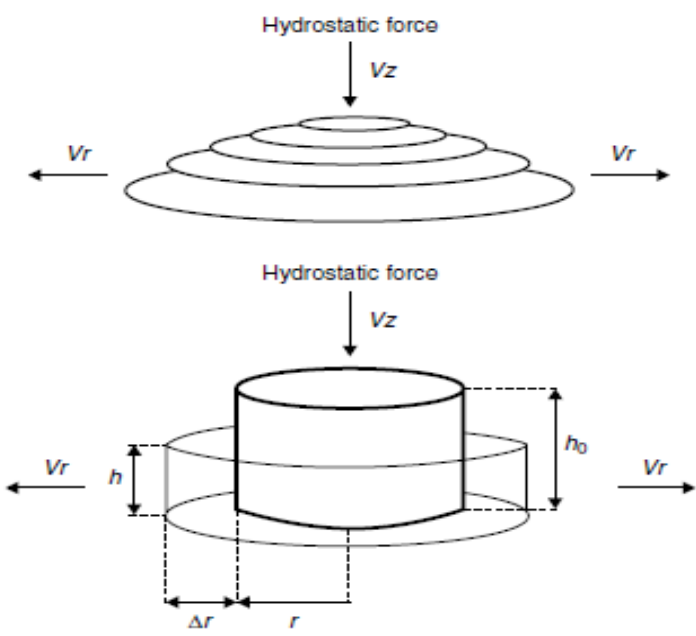

Figure 3: Model geometry for flow during spreading over a flat surface $[6,7]$.

In a study by Friedman et al. [21] the correlation between panel and objective evaluations on the developed standard scales was shown. Foods selected to represent the individual points on the scales of hardness, brittleness, chewiness, gumminess, and adhesiveness were evaluated objectively on the texturometer. The results are shown in Figures 1-4. From results we saw that the correlation is very good between the sensory evaluation by panel and the instrument. So we can replace the panel with instrument after standardization with panel results.

In a study of Safari et al. [22], because of the high cost of sensory panel testing, instrumental measurements that are used to indicate eating quality show a relationships between sensory panel assessment of eating quality attributes and $\mathrm{pH}$, cooking loss and shear force has no significant differences between genotypes for panel assessment of tenderness, juiciness, aroma liking, aroma strength, favour liking, overall acceptability and rating.

Also acoustic measures are important for the under-standing of food texture. Through the use of a combination of instrumental and acoustic approaches, it has been possible to gain a better understanding of the sensation of crispness. The structural expansion and breaking strength of extruded snacks and the relationships between the two has been shown to support sensory measures of crispness of extruded snacks [23].

Barrett et al. [24] have looked at the relationship between the structural properties of extruded snacks, fracturability using forcedeformation measures and the sensory properties of the snacks. They showed that neither density nor mean cell area alone could be used as an indicator of mechanical strength, however sensory scores could be quantified based on Fourier and fractal analysis of the compression curve. Acoustic intensity has been shown to differ between potato chip samples of differing water activities, with intensity level decreasing as water activity increased. However, this is less important for characterizing crispness than the mean sound pressure and the sound pressure level [25].

Ribeiro et al. [26] constructed the chemo metric regression model for demonstrating the inter-relationship between NIR analysis and sensory attributes of roasted coffee beans. Near Infrared Spectroscopic (NIRS) is widespread methodology for qualitative and quantitative analysis of food [27-32]. NIR spectra predicted values of lipids and proteins which attributed body, caffeine and chlorogenic acids related to bitterness, chlorogenic acids with acidity, flavour finally the cleanliness and overall quality with caffeine, trigonelline, chlorogenic acid, polysaccharides, sucrose and protein (Figures 5-8).

Sangeeta Prakash et al. [33] studied oral texture which is also one of the most important quality attributes that contribute to consumers' acceptance and preference of a food product. Oral processing of food is intricate and involves a series of processes- ingestion, mastication and finally swallowing. The mechanical and rheological properties have been widely applied to understand and describe in-mouth flow properties of a food and associated sensory perception. However, as the oral processing continues and food particle size reduces, rheology alone is no longer effective in explaining the textural and mouth feel properties of food, but the lubrication behaviour between oral surfaces becomes a dominating mechanism in relation to food texture and mouth feel. For this reason, tribology is emerging as a new discipline for food texture studies, where lubricating properties of food are measured by using an equipment that operates on the same principle used in mechanical engineering for determining the frictional properties of lubricants. Figure 9, represents the friction between interacting surfaces. From figure we can understand how the forces act and how we can develop a model and instrument with help of these mechanisms.

As showed in Figure 10, a Stribeck curve can be typically divided into three regimes - the boundary regime, the mixed regime, and the hydrodynamic regime, representing three very different friction scenarios and, in case of oral processing, different amount of food
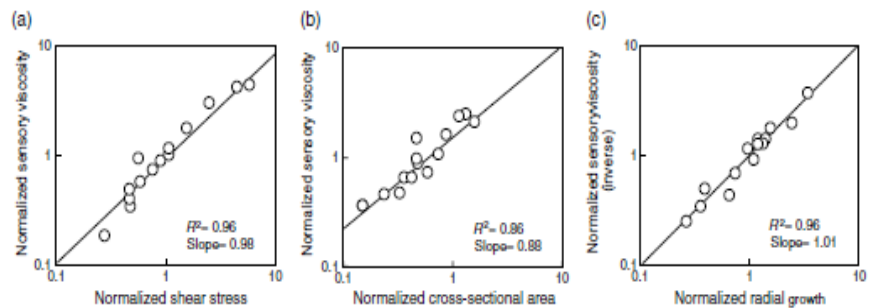

Figure 4: Normalized sensory viscosity vs. (a) normalized shear stress $n$ the mouth, (b) normalized cross-sectional area of the bottle neck filled with syrup during pouring out of a bottle, and (c) normalized radial growth of syrup puddle during spreading over a flat surface $[6,7]$. 


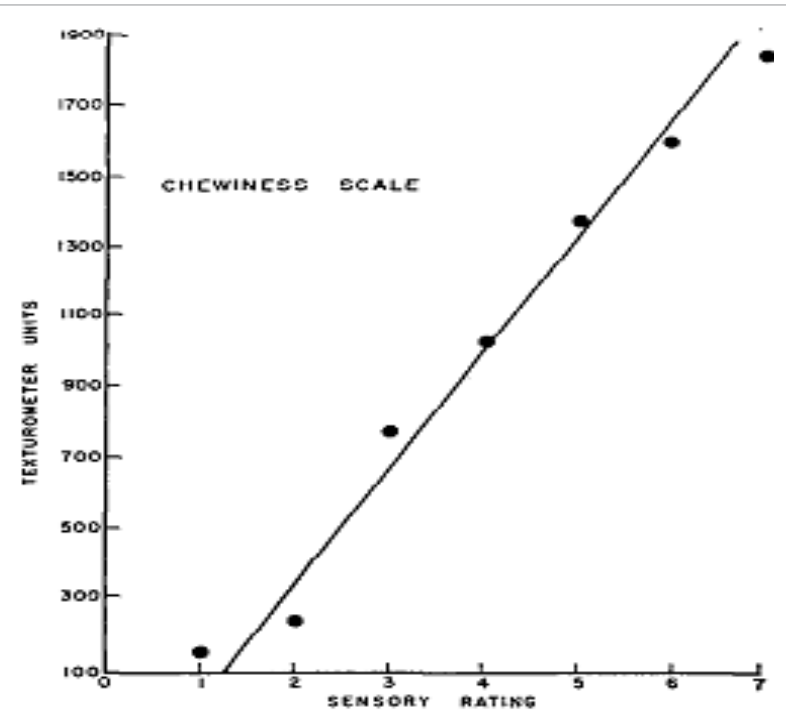

Figure 5: Correlation between the panel and the texurometer on the cheweiness.

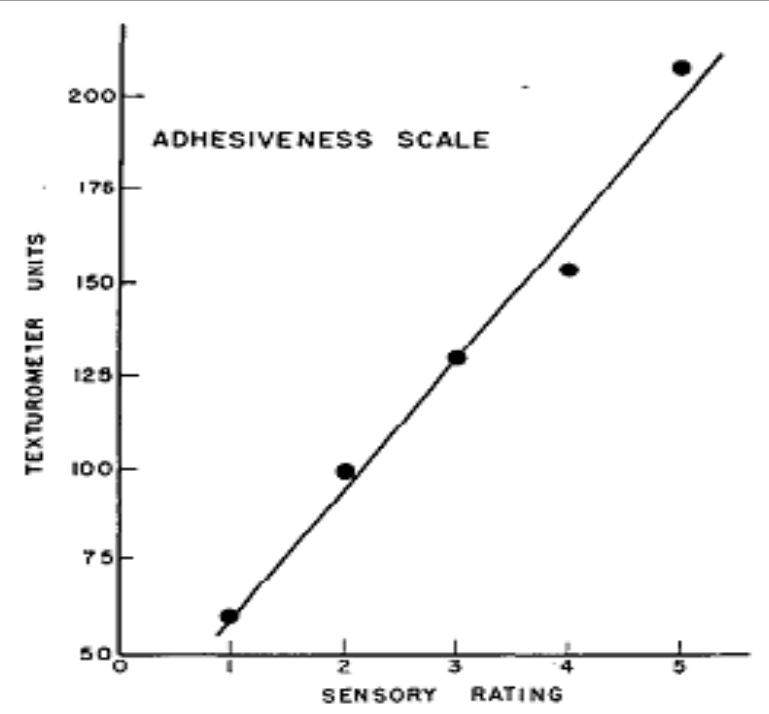

Figure 6: Corelation between the panle and the texturometer on the adhesiveness scale.

sample between the tongue and palate as highlighted. For tribological measurements of food samples elastomers are used as the bottom plates [34]. The capability of maltodextrin has been validated with a range of fluid milk with different fat percentage. Figure 11 gives Stribeck curves generated from different milk samples, where differences in friction coefficient at different sliding speeds are clearly observable. Further tests using fat-in-water emulsions thickened with maltodextrin or xanthum gum showed a relationship between friction factor and human creaminess perception.

Roudaut et al. [35] conclude in general, research works should better merge sensory and instrumental approaches for crispiness of foods. Indeed instrumental related information such as sonograms or electro-myographies data would enable a better understanding of the mental representation of texture through modelling cognitive activities from stimuli characteristics. The use of instruments for crushing of crisp samples for acoustic analysis has been suggested as a better technique for obtaining objective recordings of sounds [36].

\section{Other statistical modelling}

Statistical models are another important group of modelling approaches for correlating the objective and subjective sensory analysis which are mainly based on mathematics. These approaches are likely

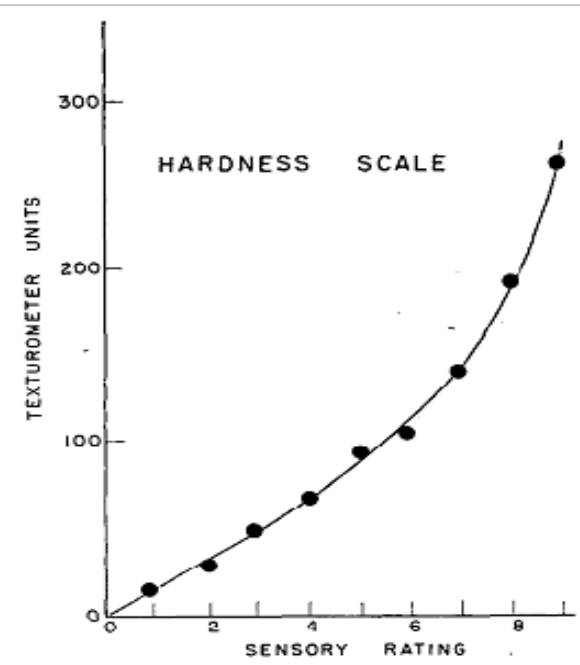

Figure 7: Correlation between panel and the texturometer on the hardness scale.

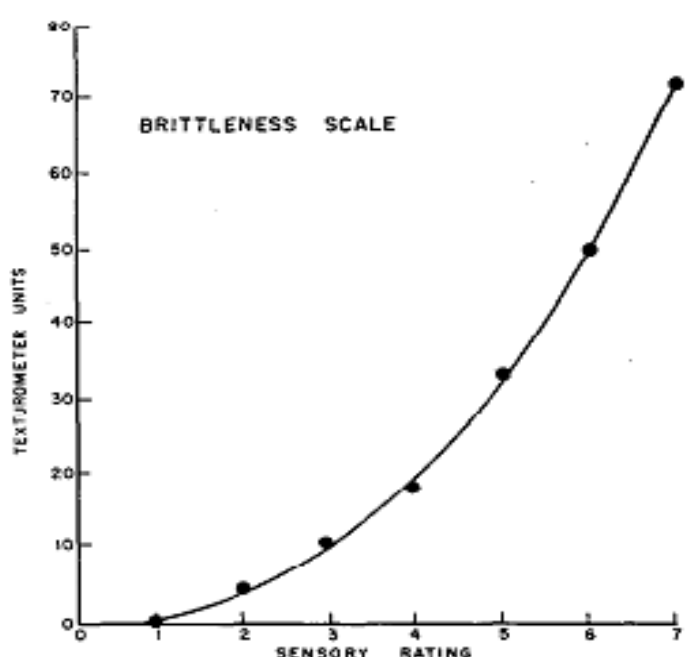

Figure 8: Correlation between the the texturometer on the brittleness scale.

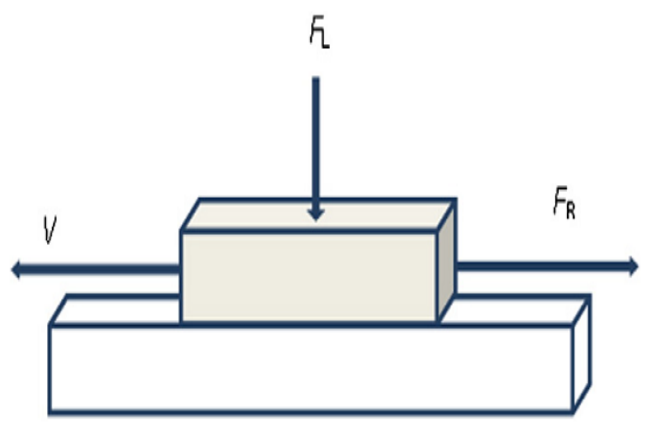

Figure 9: An illustration represents the friction between interacting surfaces. Arrows indicate directions and magnitudes of forces. FL is the normal force, $\mathrm{V}$ is the sliding speed and FR is the friction force. 
Citation: Singham P, Birwal P, Yadav BK (2015) Importance of Objective and Subjective Measurement of Food Quality and their Inter-relationship. J Food Process Technol 6: 488. doi:10.4172/2157-7110.1000488

Page 6 of 7

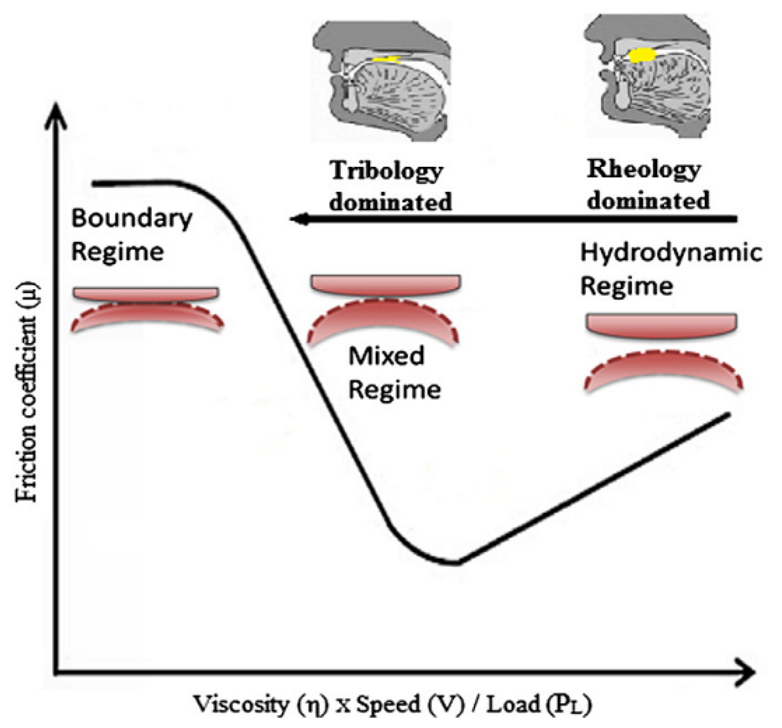

Figure 10: A Stribeck curve where the friction coefficient is plotted against the combined parameters of the viscosity, entrainment speed and the surface load.

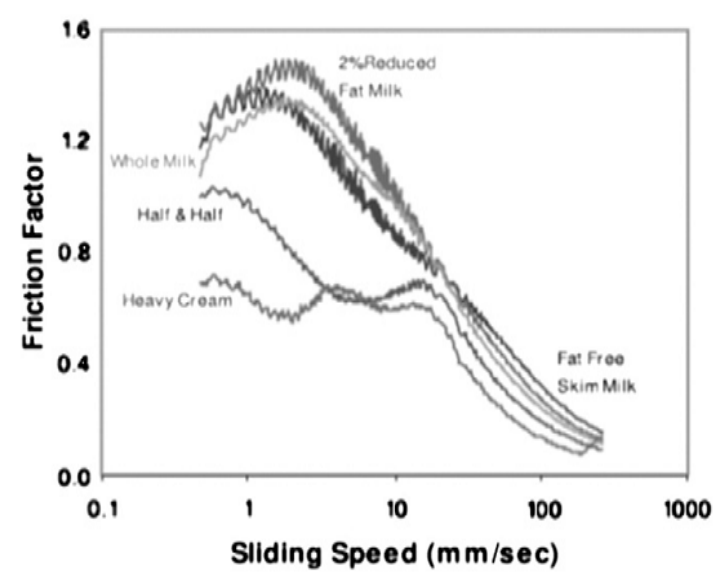

Figure 11: Friction factor as a function of sliding speed foe fluid milks with different fat percentage adapted from Baier et al. [34]

to be adopted when the fundamental mechanism of the process or the correlation of parameters is unclear [37]. The models are applied to correlate the non-mechanical data and food texture. Partial Least Square Regression model was applied to correlate the data on firmness of tomato, banana, mango, peach and kiwifruit to the near infrared spectral data. Response surface methodology was applied by Saeleaw et al. [38] to analyse the effects of independent variables on response parameters of snack. Weibull model was employed by Rojo and Vincent [39] to statistically analyse the crispness of crisps. At the same time, some other statistical methods of data analysis, such as one/two/threeway analysis of variance (ANOVA) and principle component analysis (PCA), are also fairly often used in sensory evaluation and instrumental measurement [40-43]. Furthermore, artificial neural network, a nonlinear statistical data modelling tool, was used to correlate the values of fluid mechanical stresses during swallowing to the sensorial texture perception [44].

Also flash profiling appeared as a quick alternative, which in the case of the fish nuggets cooked by different procedures, presented similar results than QDA, with the added advantage that using semi trained assessors instead of trained is possible. As QDA is a very accurate descriptive method, the time and effort necessary for training and maintaining a panel for hot served foods with contrasting textural layers, such as nuggets, could be long and expensive, and requires careful manipulation of the samples [45].

\section{Conclusion}

Both sensory and objective methods are important in evaluation of food quality and the two methods complement to each other. Sensory analysis is essential for the new products development, as only consumers are main concern who can tell whether product is acceptable or not. However, objective testing is also important, especially for routine control of food products. So it can be concluded that sensory and objective tests have inter-relationship on each other for determining overall quality and acceptability biologically and mechanically.

\section{References}

1. Magni M (1999) A philosophy for sensory science. Food Quality and Preference 10: 233-244.

2. Moskowitz HR (2002) The intertwining of psychophysics and sensory analysis: historical perspectives and future opportunities-a personal view. Food Quality and Preference 14: 87-98.

3. Kokini JL (1976) Predicting liquid food texture from fluid dynamics and lubrication theory. Carnegie-Mellon University, Pittsburg, USA.

4. Kokini JL, Poole M, Mason P, Miller S, Stier E (1984) Identification of key textural attributes of fluid and semi-solid foods using regression analysis. Journal of Food Science 49: 47-51.

5. Kokini JL, Cussler EL (1983) Predicting the texture of liquid and melting semisolid foods. Journal of Food Science 48: 1221-1225.

6. Elejalde CC, Kokini JL (1992) Identification of key textural attributes of viscoelastic syrups by regression analysis. Journal of Food Science 57: 167171.

7. Elejalde CC, Kokini JL (1992) The psychophysics of pouring, spreading and in-mouth viscosity. Journal of Texture Studies 23: 315-336.

8. Dijksterhuis GB (1997) Multivariate data analysis in sensory and consumer science: An overview of developments. Trends in Food Science and Technology 6: 206-211.

9. Stone H, Sidel JL (1993) Sensory evaluation practices.Food Science and Technology, Academic Press, Inc.

10. Karima A, Moussaoui, Varela P (2010) Exploring consumer product profiling techniques and their linkage to a quantitative descriptive analysis. Food Quality and Preference 21: 1088-1099.

11. Jason RS, Michael JR, Boehma, Stefan K (2013) Oral processing, texture and mouthfeel: From rheology to tribology and beyond. Current Opinion in Colloid and Interface Science 18: 349-359.

12. Khori A, Nurasyikin (2013) Production of instant fish and maize soup powder by extrusion process. Food Science and Technology in the Faculty of Applied Sciences.UniversitiTeknologi MARA.

13. Pangborn RM (1987) Sensory science a research: Achievements, needs and perspectives. In M. Martens, Dalen GA, Russwurm H Flavour science and technology 275-289, London: John Wiley and Sons, USA.

14. Costa F, Cappellin L, Longhi S, Guerra W, Magnago P, et al. (2011) Assessment of apple (Malusdomestica Borkh.) fruit texture by a combined acoustic-mechanical profiling strategy. Post harvest Biology and Technology 61: $21-28$

15. Kim EHJ, Corrigan VK, Wilson AJ, Waters IR, Hedderley DI, et al. (2012) Fundamental fracture properties associated with sensory hardness of brittle solid foods. Journal of Texture Studies 43: 49-62.

16. Wang R, Zhou W, Isabelle M (2007) Comparison study of the effect of green tea extract (GTE) on the quality of bread by instrumental analysis and sensory evaluation. Food Research International 40: 70-479. 
Citation: Singham P, Birwal P, Yadav BK (2015) Importance of Objective and Subjective Measurement of Food Quality and their Inter-relationship. J Food Process Technol 6: 488. doi:10.4172/2157-7110.1000488

17. Shama F, Sherman P (1973) Identification of stimuli controlling the sensory evaluation of viscosity II. Oral methods.Journal of Texture Studies 4: 111-118.

18. Shama F, Parkinson C, Sherman P (1973) Identification of stimuli controlling the sensory evaluation of viscosity I. Non-oral methods. Journal of Texture Studies 4: 102-110.

19. Kokini JL, Kadane JB, Cussler EL (1977) Liquid texture perceived in the mouth. Journal of Texture Studies 8: 195-218.

20. Szczesniak AS, Kahn EL (1971) Consumer awareness of and attitudes to food texture. Journal of Textural Studies 2: 28-295.

21. Friedman H, Whitney J, Szczesniak AS (1963) The texturometer-a new instrument for objective texture measurements. Journal of food science 28 : 390-396

22. Safari E, Fogarty NM, Ferrier GR, Hopkins LD (2001) Diverse lamb genotypes 3. A eating quality and the relationship between its objective measurement and sensory assessment. Gilmour Meat Science 57: 153-159.

23. Faller JY, Hyman H (1996) Sensory and physical properties of extruded potato puffs. Journal of Sensory Study 11: 227-245.

24. Barrett AH, Cardello AV, Lesher LL, Taub IA (1994) Cellularity mechanical failure and textural perception of corn meat extrudates. Journal of Texture Studies 25: 77-95.

25. Seymour SK, Hamann DD (1988) Crispness and crunchiness of selected low moisture foods. Journal of Textural Studies 19: 79-95.

26. Ribeiro JS, Ferreiraa MMC, Salva TJG (2011) Chemometric models for the quantitative descriptive sensory analysis of Arabica coffee beverages using near infrared spectroscopy. Talanta 83: 1352-1358.

27. Chen Q, Zhao J, Zhang, Wang HX (2006) Analytica Chimica Acta.

28. Cozzolino D, Smyth HE, Lattey KA, Cynkar W, Janik L, et al. (2006) Analytica Chimica Acta.

29. Cen H, He Y (2007) Trends in Food Science and Technology 18: 72.

30. Karoui R, Pillonel L, Schaller E, Bosset JO, Baerdemaeker DJ (2006) Food Chemistry 101: 1121

31. Pizarro C, Esteban-Díez I, González-Sáiz JM, Forina M (2007) Journal of Agriculture Food Chem 55: 7477.

32. Pedro AMK, Ferreira MMC (2009) Applied Spectroscopy 63: 1308.

33. Sangeeta P, Daniel D, Yi T, Jianshe C (2013) Applications of tribology in studying food oral processing and texture perception. Food Research International 54: 1627-1635.
34. Baier S, Elmore D, Guthrie B, Lindgren T, Smith S, et al. (2009) A new tribiology device for assessing mouth feel attributes of foods. 5th International Symposium on Food Structure and Rheology. Switzerland.

35. Roudaut G, Dacremont C, Valles P B, Colas B, LeMeste M (2002) Crispness: a critical review on sensory and material science approaches. Trends in Food Science and Technology 13: 217-227

36. Mohamed AAA, Jowitt R, Brennan JG (1982) Instrumental and Sensory Evaluation of Crispness: 1. In Friable Foods. Journal of Food Engineering 1 : $55-75$

37. Lan C, Umezuruike LO (2013) Approaches to analysis and modelling texture in fresh and processed foods- A review. Journal of Food Engineering 119: 497507.

38. Saeleaw M, Dürrschmid K Schleining G (2012) The effect of extrusion conditions on mechanical-sound and sensory evaluation of rye expanded snack. Journal of Food Engineering 110: 532-540.

39. Rojo FJ, Vincent JFV (2009) Objective and subjective measurement of the crispness of crisps from four potato varieties. Engineering Failure Analysis 16 : 2698-2704.

40. Alvarez MD, Fernández C, Jiménez MJ, Canet W (2011) Texture of extra virgin olive oil-enriched mashed potatoes: sensory, instrumental and structural relationships. 42: 413-429.

41. Ares G, Budelli E, Bruzzone F, Giménez A, Lema P (2012) Consumers' texture perception of milk desserts. I-Relationship with rheological measurements. Journal of Texture Studies 43: 203-213.

42. Benedini R, Parolari G, Toscani T, Virgili R (2012) Sensory and texture properties of Italian typical dry-cured hams as related to maturation time and salt content. Meat Science 90: 431-437.

43. Zdunek A, Cybulsk J, Konopacka D, Rutkowski K (2010) New contact acoustic emission detector for texture evaluation of apples. Journal of Food Engineering 99: 83-91.

44. Rauh C, Singh J, Nagel M, Delgado A (2012) Objective analysis and prediction of texture perception of yoghurt by hybrid neuro-numerical methods. International Dairy Journal 26: 2-14.

45. Albert A, Varela P, Salvador A, Hough G, Fiszman S (2011) Overcoming the issues in the sensory description of hot served food with a complex texture. Application of QDA, flash profiling and projective mapping using panels with different degrees of training. Food Quality and Preference 22: 463-473. 